\title{
Las competencias geopolíticas de Nicaragua, Honduras, Colombia y Costa Rica por su territorio ante la Corte Internacional de Justicia * The geopolitical competitions of Nicaragua, Honduras, Colombia and Costa Rica by its territory at the International Court of Justice
}

\section{Pablo Rivas Pardo}

Pablo Rivas Pardo es Investigador Asociado del Instituto de Estudios Internacionales de la Universidad Arturo Prat, Chile. E-mail: p.rivas.pardo@gmail.com

\section{resumen}

El análisis se centra en las competencias geopolíticas por territorio ante la Corte Internacional de Justicia, que involucran a Nicaragua, Honduras, Colombia y Costa Rica con respecto a sus límites internacionales. Para aquello, dos secciones componen el artículo: primero, la discusión teórica del concepto territorio de Stuart Elden, más la propuesta metodológica de análisis; segundo, las demandas de los Estados seleccionados y las sentencias de la Corte. Los resultados muestran que las competencias geopolíticas por el territorio incluyen tierra y mar; que los Estados replican un rol cuando tienen el estatus de demandante, ocurriendo lo mismo cuando son demandados; que la Corte sentencia mediante votación, sin aceptar tesis maximalistas y usando la cartografía para representar el territorio; y por último, que la territorialización es un proceso continuo.

\section{summary}

The analysis focuses on the geopolitical competitions by territory before the International Court of Justice, which involve Nicaragua, Honduras, Colombia and Costa Rica concerning their international boundaries. For that, two sections make up the article: first, the theoretical discussion of the concept of territory of Stuart Elden and the methodological proposal of analysis; second, the demands of the selected States and the judgments of the Court. The results show that geopolitical competitions for the territory include land and sea; the states replicate the role when they are applicants and defendant; the sentence of the Court are by vote, without using maximalist thesis and using cartography; and finally, the territorialization is a continuous process.

\section{palabras clave}

geopolítica / Nicaragua / Honduras / Colombia / Costa Rica / territorio / corte internacional de justicia

\section{keywords}

geopolitics / Nicaragua / Honduras / Colombia / Costa Rica / territory / international court of justice 


\section{Introducción}

La demanda de Nicaragua contra Honduras ante la Corte Internacional de Justicia (CIJ), en el año 1999, inició un período de demandas que disputan límites terrestres, límites marítimos y cuestiones fronterizas en América latina (Abello, 2013). Entre éstas, se destacan los casos de Nicaragua contra Colombia, Ecuador contra Colombia y Bolivia contra Chile que, junto con otras, han aportado jurisprudencia a la CIJ y al derecho internacional (Wojcikiewicz y Sorel, 2017).

Estas demandas corresponden a competencias geopolíticas que, para Miguel Barrios, implican disputas "por controlar territorios, recursos y posiciones geográficas importantes" (2009: 194) siendo éste el objetivo de un Estado demandante ante la CIJ. Tales competencias no son nuevas en América latina, inclusive, ha existido una tendencia a disputas por problemas limítrofes y fronterizos de herencia colonial (Dellanegra, 2010). Sin embargo, lo nuevo es que la CIJ resuelve tales competencias; como explican Karen Manzano y Diego Jiménez, la CIJ ha hecho "distribución del poder (...) al ajustar los espacios geopolíticos" (2016: 189-190) en razón de que las demandas abordan conflictos de soberanía.

La distribución de poder por medio de las sentencias, se refiere, por ejemplo, a la creación de límites marítimos, como la demanda de Nicaragua contra Honduras (Kojima 2017), Nicaragua contra Colombia (Tassin, 2017) y Perú contra Chile (Scovazzi, 2017). Para Carlos Bellei, los Estados demandantes, al usar la CIJ para sus competencias geopolíticas, hacen una "disputa justiciable" (2015: 105) por tener consideraciones jurídicas y no políticas, por lo cual, la competencia geopolítica adquiere una solución en derecho.

Como corolario, los Estados de América latina han llevado competencias geopolíticas ante la CIJ, buscando soluciones justiciables por cuestiones territoriales, es decir la CIJ se convierte y consolida como una institución que distribuye poder.

Como indica el Cuadro $\mathrm{N}^{\mathrm{o}}$ 1, hubo 17 demandas entre distintos Estados de América latina desde 1999, seleccionándose las controversias que involucran a Nicaragua por delimitaciones ya sentenciadas. En total, se analizan cuatro casos, unificándose las dos de Costa Rica.

\begin{tabular}{|c|c|c|c|c|}
\hline \multicolumn{5}{|c|}{$\begin{array}{c}\text { Cuadro } \mathrm{N}^{\circ} 1 \\
\text { Demandas entre los Estados de América latina en la Corte Internacional de Justicia desde } 1999\end{array}$} \\
\hline $\mathbf{N}^{\circ}$ & Estados & Asunto & Inicio & Fin \\
\hline 1 & Nicaragua v. Honduras* & Disputa territorial y marítima & 1999 & 2007 \\
\hline 2 & Nicaragua v. Colombia* & Disputa territorial y maritima & 2001 & 2012 \\
\hline 3 & El Salvador v. Honduras & Revisión del Fallo de la CIJ de 11/09/92 & 2002 & 2003 \\
\hline 4 & Costa Rica v. Nicaragua & Disputa sobre derechos de navegación y derechos conexos & 2005 & 2009 \\
\hline 5 & Argentina v. Uruguay & Fábricas papeleras en el río Uruguay & 2006 & 2010 \\
\hline 6 & Perú v. Chile & Disputa marítima & 2008 & 2014 \\
\hline 7 & Ecuador v. Colombia & Rociado herbicida aéreo & 2008 & 2013 \\
\hline 8 & Honduras v. Brasil & Ciertas cuestiones concernientes a Relaciones Diplomáticas & 2009 & 2010 \\
\hline 9 & Costa Rica v. Nicaragua & Ciertas Actividades realizadas por Nicaragua en el Área Fronteriza & 2010 & 2015 \\
\hline 10 & Nicaragua v. Costa Rica & Construcción de una carretera en Costa Rica a lo largo del río San Juan & 2011 & 2015 \\
\hline 11 & Bolivia v. Chile & Obligación de negociar el acceso al Océano Pacífico & 2013 & 2018 \\
\hline 12 & Nicaragua v. Colombia & Cuestión de la delimitación de la plataforma continental & 2013 & - \\
\hline 13 & Nicaragua v. Colombia & Violaciones de derechos soberanos y espacios marítimos en el Mar Caribe & 2013 & - \\
\hline 14 & Costa Rica v. Nicaragua* & Delimitación marítima en el Mar Caribe y el Océano Pacífico & 2014 & 2018 \\
\hline 15 & Chile v. Bolivia & Disputa sobre el estado y el uso de las aguas del Silala & 2016 & - \\
\hline 16 & Costa Rica v. Nicaragua* & Límite terrestre en la parte norte de Isla Portillos & 2017 & 2018 \\
\hline 17 & Guyana v. Venezuela & Laudo Arbitral de 03/10/1899 & 2017 & - \\
\hline
\end{tabular}


En consecuencia, las preguntas de investigación son: ¿Cuáles son las características de las competencias geopolíticas entre los casos seleccionados? Y ¿Cuáles son las características de las sentencias de la CIJ para solucionar las competencias geopolíticas entre los casos seleccionados?

Para responder estas preguntas, el análisis se hace desde la teorización del territorio del académico Stuart Elden. Como señala Roszko (2015), el trabajo de Elden permite comprender la conexión entre la soberanía con el territorio, los recursos y la población, dando importancia a la tecnología. De manera similar, Blomley (2016) reflexiona sobre el aporte de Elden para la comprensión de la realidad del territorio, mediante la separación de las categorías de análisis, como son la tierra, la propiedad y el terreno, sumando también, la propuesta de cálculo del espacio.

A modo de resultado, las respuestas cumplen dos objetivos: analizar el territorio importante por controlar, analizándose al Estado demandante; y analizar la distribución del poder por medio de la sentencia de la CIJ.

El artículo consta de dos partes. La primera, es el marco teórico sobre el concepto de territorio de Stuart Elden, más una explicación metodológica para el análisis. La segunda, es el análisis de los casos, basado en fuentes primarias de las demandas y de las sentencias. Por último, se concluye respondiendo las preguntas de investigación.

\section{El territorio según Stuart Elden}

Stuart Elden señala en varias publicaciones que el concepto territorio se ha dado por sabido, subrepresentando su estudio, siendo esto su motivación investigativa. Por lo que, gran parte de sus publicaciones se dedican a tal labor, aportando una especificidad de conocimiento para analizar y comprender la realidad.

En su artículo Missing the Point, Elden (2005) propone como idea principal, que el territorio se entienda como un espacio "calculable" (2005: 08) valorizando las ciencias matemáticas y el trabajo científico ejercible sobre un espacio, sometiéndolo a cálculos para dimensionarlo. El ejercicio de calcular implica la confección de un mapa, teniendo por desenlace "la exclusión y el control" (2005: 15) del y en el territorio. Entonces, la cartografía como consecuencia del cálculo del espacio crea un territorio para ejercer una soberanía.

Luego en Governmentality, calculation, territory, Elden (2007) utiliza la idea de cálculo de Foucault para la población, pero para el territorio. En este artículo, él profundiza la relación espacio y cálculo, describiendo la ocupación del espacio por medio de estrategias aplicadas, como son el "mapeo, orden, medición y demarcación" (2007: 578), regulando la circulación interna del espacio. Lo anterior, se expresa con el concepto territorialización, surgiendo un "dueño, distribución, mapeo, cálculo, límites y control" (2007: 578) entre otras cosas.

Complementando estos dos artículos, Raffestin (2012) sostiene que el espacio puede ser una realidad material o inmaterial, por lo cual, el cálculo que propone Elden, podría ser una acción en terreno o una representación del mismo. Como paso siguiente a calcular, Behr (2007) indica que los límites y demarcación del territorio permiten su protección y control, es decir, luego de definir las líneas que 
componen el territorio, comienza el control sobre éstos, teniendo como cualidades, según Buxbaum (2009), de un Estado como un territorio geográfico particular con jurisdicción dado por una autoridad soberana.

A propósito de Behr, vale precisar la diferencia entre límite y frontera. Mientras límite es un criterio abstracto que divide soberanías entre Estados contiguos, y que por medio de la demarcación se hace real en el terreno y se representa en un mapa; la frontera es un territorio cercano al límite entre Estados contiguos. Por ejemplo, la demanda del Perú contra Chile de 2008, fijó un límite internacional marítimo demarcado en un mapa, mientras que la demanda de Argentina contra Uruguay de 2006, reguló empresas papeleras ubicadas en Uruguay, en un territorio cercano al límite internacional con Argentina. En los casos de este artículo, se escogieron casos de límites, no de frontera.

Volviendo a Elden (2010), la idea de territorio como una categoría de cálculo por medio de distintas técnicas está presente en Land, terrain, territory, donde propone definiciones para diferentes categorías similares. Por ejemplo, tierra, junto con ser una propiedad, la define como un "recurso finito que es distribuido, ubicado y con dueño (...) es un recurso sobre el cual hay competencia" (2010: 804); y terreno, que lo expone como "una relación de poder (...) el control el cual permite el establecimiento y mantención del orden" (2010: 804). Por lo que, Elden desarrolla ideas que terminan afirmando que la meta de la territorialización del espacio es finalmente su control, el cual podría generar una competencia geopolítica.

En su libro The Birth of Territory (2013a) estudia diversos momentos históricos de la humanidad y la relación con el territorio. En este caso, sostiene que territorio es "un proceso, de hacer y rehacer, moldeado y moldeable, activo y reactivo" (2013a: 17). Luego, más adelante, vuelve a las estrategias de aplicación, señalándolas como un "orden para establecer lo que es realmente controlado" (2013a: 324). Con eso, suma la idea de que el territorio es un proceso perpetuo, que complementado con lo anterior, se explica en parte por la competencia por su control.

Por último, en How Should We Do the History of Territory? (2013b), vuelve a la idea de Foucault de cálculo para medir la población, el cual "deviene en objeto de gobernabilidad" (2013b: 12) es decir, que las estrategias aplicadas al territorio tienen el fin de ejercer poder. Elden reitera que el cálculo es "la forma en que el territorio es normalizado" (2013b: 14) y que el territorio "es un proceso continuo de transformación, regulación y gobierno" (2013b: 17) es decir, es un proceso con competencias de su control normado. Complementando la idea, Xuan(2015), sustenta que la territorialización en los Estados modernos se compone de personas y recursos, para lo cual se crean regulaciones que define quiénes pueden usarlas.

A modo de resumen de la propuesta de Elden, el espacio parte con un cálculo para dimensionarlo y así convertirlo en territorio por medio de las estrategias de aplicación o territorialización; luego, el territorio, es representado en una cartografía donde se demarcan los límites, presentándose como una herramienta de poder. Posteriormente, está el ejercicio del poder, dado por un soberano y una jurisdicción, por lo cual, hay un territorio que podría ser motivo de disputa, comprendido como una competencia geopolítica. 
Como resultado analítico entre los casos seleccionados y el concepto de territorio de Elden: se debe analizar la conformación del espacio que propone el Estado demandante, en especial, los argumentos para que ese espacio disputado se transforme en territorio propio; y se debe analizar la sentencia de la CIJ, específicamente, las estrategias de aplicación más la cartografía que establecen por votación los jueces de la CIJ, definiendo cómo el espacio del demandante se transforma en territorio para los Estados de la controversia.

\section{Las competencias geopolíticas por el territorio}

De manera histórica y regional, los Estados de América Central han tenido competencias geopolíticas por territorios importantes desde larga data. Un ejemplo es el Golfo de Honduras (Reichert, 2017), cuya soberanía e influencia fue disputada entre el Imperio español y el Reino Unido; durante el Siglo XIX entre el Reino Unido y Francia; y desde el Siglo XX, Estados Unidos ha intentado tener una influencia política, económica y militar. Otro ejemplo es el Golfo de Fonseca (Medina, 2013), disputado entre El Salvador, Nicaragua y Honduras desde que son repúblicas.

En el Mar Caribe, el archipiélago San Andrés (Sánchez-Aguirre, 2015) ha sido un espacio de disputa entre Estados Unidos, Colombia y Nicaragua, que durante la Guerra Fría alineó a Nicaragua con Rusia y Estados Unidos con Colombia, firmando estos últimos el Tratado Vásquez-Saccio de 1972, quedando los cayos Roncador, Serrana y Quitasueño para Colombia. Sin embargo, el espacio geográfico del archipiélago San Andrés (Alvarado, 2014) fue redisputado por el régimen sandinista en 1980, al declarar nulo el tratado Esguerra-Bárcenas de 1928, firmado entre Colombia y Nicaragua, por haberse suscrito bajo ocupación estadounidense.

Algo similar ocurre entre Costa Rica y Nicaragua. En este caso, parte del límite internacional entre ambos es el río San José (Quesada, 2014), que ha sido un espacio de competencia geopolítica, que para Nicaragua asegura la conexión bioceánica y para Costa Rica la libre navegación. El asunto, es que a pesar de la existencia de tratados bilaterales, éstos no fueron suficientes para evitar nuevas competencias geopolíticas.

\section{Nicaragua contra Honduras}

En su demanda contra Honduras, Maritime delimitation between Nicaragua and Honduras in the Caribbean Sea (República de Nicaragua, 1999), Nicaragua señala que la disputa es por "asuntos legales subsistentes [...] acerca de una delimitación marítima” (República de Nicaragua, 1999: 02) definiendo el espacio para territorializar y territorio importante.

El gobierno de Arnoldo Alemán demandó, señalando la inexistencia de un límite marítimo, por lo que éste debía hacerse por medio de una bisectriz, incluyendo una serie de cayos; en contra, la postura de Honduras era la existencia de un límite fijado por un paralelo (Ver Anexo 1). Por lo cual, la competencia geopolítica por un límite marítimo y la soberanía de los cayos sólo era real para Nicaragua. Dado lo anterior, la estrategia para conseguir el territorio importante fue hacer justicia- 
ble la competencia geopolítica y que la CIJ distribuyera poder por medio de la territorialización.

Como señala la demanda, el Estatuto de la CIJ y su Reglamento, junto con el Pacto de Bogotá (República de Nicaragua, 1999: 02) hacían justiciable esta competencia geopolítica, solicitando que la CIJ determinara:

El curso del límite marítimo único entre las áreas del mar territorial, la plataforma continental y la zona económica exclusiva pertenecientes respectivamente a Nicaragua y Honduras, de conformidad con los principios equitativos y las circunstancias relevantes reconocidas por el derecho internacional general, según sea aplicable a tal delimitación de un límite marítimo único (República de Nicaragua, 1999: 06).

Entonces, la competencia geopolítica por el límite marítimo conformó como espacio a territorializar, es decir, territorios importantes: al mar territorial, la plataforma continental y la zona económica exclusiva, implicando los cayos. Así también, y siguiendo la idea de solución justiciable, se solicitó a la CIJ hacerlo por medio del derecho internacional, principio de equidad y circunstancias relevantes, que posibilitan la creación de un límite marítimo.

Desde la perspectiva del territorio como proceso, Nicaragua muestra una serie de antecedentes de cómo el espacio a territorializar ha querido convertirlo en su territorio. En detalle, la Constitución Política de 1948, que incluía una plataforma continental para el Océano Atlántico y el Pacífico; los decretos de 1958, que hacen referencia a la explotación de recursos naturales, destacándose el petróleo; la declaración de zona de pesca de 1965, que alcanzaba las 200 millas marítimas para ambos océanos; y diversas leyes internas para concesiones petroleras y de pesca (República de Nicaragua, 1999: 02). A lo anterior, suma el Laudo Arbitral hecho por el Rey de España en 1906 y la intervención de la OEA en 1962 (República de Nicaragua, 1999: 04). Como último evento de este proceso, el gobierno de Alemán trató de solucionarlo bilateralmente, pero tras la cancelación de una reunión de los Ministros de Relaciones Exteriores por parte de Honduras, tomó la decisión de interponer la demanda ante la CIJ (República de Nicaragua, 1999: 04).

En resumen, la demanda fue una alternativa a la decisión de no tratar el asunto de manera bilateral por parte de Honduras. Luego, con la demanda, se institucionaliza una competencia geopolítica, donde territorio importante es la delimitación del Mar Caribe, incluyendo un grupo de cayos. Asimismo, Nicaragua en el contexto de América Central y bilateral con Honduras, abrió una nueva etapa del proceso de territorialización que han vivido varios Estados de la subregión.

Como resultado de esta competencia, la CIJ en su sentencia Territorial and Maritime Dispute between Nicaragua and Honduras in the Caribbean Sea (Corte Internacional de Justicia, 2007a), construye un límite marítimo único entre ambos Estados. En el "Título 9: Cláusula Operativa" (Corte Internacional de Justicia, 2007a: 105-108) mediante votación, sentenció: $1^{\circ}$ ) Honduras es soberano de Cayo Bobel, Cayo Savanna, Cayo Port Royal y Cayo Sur (Ver Anexo 2), por unanimi- 
dad; $2^{\circ}$ ) el límite marítimo tiene su punto de partida en la coordenada $15^{\circ} 00^{\prime} 52^{\prime \prime}$ $\mathrm{N}$ y $83^{\circ} 05^{\prime} 58^{\prime \prime} \mathrm{O}$ " (Anexo 3), por 15 votos contra $2 ; 3^{\circ}$ ) desde el punto de partida, la bisectriz va por la Azimut $70^{\circ} 14^{\prime} 41,25^{\prime}$ " rodeando los cayos para continuar por la misma azimut (Ver Anexo 4), por 14 votos contra 3, $4^{\circ}$ ) ambos Estados deben negociar el límite internacional entre el fin del límite terrestre y el punto de partida del límite marítimo, por 16 votos contra 1.

De la sentencia, se extraen tres ideas. Primero, que el espacio puesto en disputa por Nicaragua fue territorializado parcialmente por la CIJ, dado que se formaliza un asunto pendiente, que es el límite entre el fin del límite terrestre y el inicio del límite marítimo. Por lo cual, el proceso de territorialización y conformación del territorio continúa. Segundo, que de las cuatro votaciones, sólo en la primera existió unanimidad, en las otras si bien hubo votos mayoritarios, no existió unanimidad de pensamiento para hacer la territorialización. Entonces, los criterios aplicados para la medición del espacio y conformación en territorio son variables. Tercero, los territorios importantes quedaron repartidos: los cayos y el mar territorial que los rodea quedaron para Honduras; las posturas maximalistas de ambos Estados fueron rechazadas, proponiéndose un punto de partida para la bisectriz que divide el mar territorial, la zona económica exclusiva y la plataforma continental. Ambos casos, como se aprecia en los anexos, ocuparon técnicas de cálculo del espacio para luego hacer el mapeo del mismo y representarlo cartográficamente. Por lo que, la tecnología importa para la resolución de conflicto, al demarcar el territorio.

\section{Nicaragua contra Colombia}

Nuevamente el gobierno de Arnoldo Alemán presentó una demanda, pero en este caso contra Colombia, que fue la Territorial and Maritime dispute (Nicaragua v. Colombia) (República de Nicaragua, 2001). Similar a la demanda anterior, la disputa consiste en "asuntos legales $[\ldots]$ con respecto al título del territorio y la delimitación marítima" (República de Nicaragua, 2001: 01) señalando la tierra y el mar como espacio territorio importante para territorializar.

Otra similitud, es que Nicaragua afirma la existencia de un asunto pendiente y Colombia lo niega. Para Nicaragua, al norte, sur y este del meridiano 82, la soberanía debía ser suya, incluyendo los espacios insulares (Ver Anexo 5, Anexo 6 y Anexo 7). En consecuencia, nuevamente la competencia geopolítica es solo para el demandante, obligando al demandado a una competencia geopolítica por medio de una disputa justiciable, siendo la CIJ la que distribuye poder y territorializa.

Se repite, como en el caso anterior y en los dos casos siguientes, que el Pacto de Bogotá, el Reglamento y Estatuto de la CIJ (República de Nicaragua, 2001: 02) hacen justiciable la competencia geopolítica, solicitando que la CIJ declare:

Que la República de Nicaragua tiene soberanía sobre las islas de Providencia, San Andrés y Santa Catalina y todas las islas y cayos de los anexos, y también sobre los cayos Roncador, Serrana, Serranilla y Quitasueño en la medida en que sean capaces de apropiarse $[. .$.$] determine el curso del límite marítimo único entre$ 
las áreas de la plataforma continental y la zona económica exclusiva pertenecientes respectivamente a Nicaragua y Colombia, de conformidad con los principios equitativos y circunstancias relevantes reconocidas por el derecho internacional general, según sea aplicable a tal delimitación de un límite marítimo único" (República de Nicaragua, 2001: 08).

En consecuencia, dos son los territorios importantes de esta competencia geopolítica: las islas y cayos, que es la tierra; más el límite marítimo internacional, compuesto por la plataforma continental y la zona económica exclusiva, que es el mar. La territorialización de éstos se solicita desde el derecho internacional, el principio de equidad y las circunstancias relevantes, repitiendo en su totalidad la lógica de la demanda anterior.

Desde la perspectiva nicaragüense, su soberanía por la tierra en disputa, viene desde el Imperio español, la Capitanía General de Guatemala y la Federación Centroamericana (República de Nicaragua, 2001: 02). También, señala el desarrollo del derecho internacional sobre la exploración y explotación de recursos naturales desde 1945; la Convención del Mar de 1982; y vuelve a mencionar la Constitución Política de 1948, los decretos de 1958 y declaración de zona de pesca de 1965 (República de Nicaragua, 2001: 04). Sobre lo bilateral, señala capturas marítimas hechas por fuerzas colombianas al este y oeste del meridiano 82 con barcos de nacionalidad o licencia nicaragüenses; y que al tratar de abordar el tema directamente, el gobierno colombiano sostuvo que todo estaba resuelto por un tratado internacional (República de Nicaragua, 2001: 06).

$\mathrm{Al}$ igual que el caso anterior, Nicaragua decide unilateralmente la demanda, por no ser factible abordar el tema bilateralmente. Como proceso, esta competencia geopolítica viene desde la colonia, teniendo como territorio importante la delimitación marítima y la soberanía de cayos e islas.

Antes de la sentencia final, Colombia presentó una excepción preliminar a la demanda, para desestimar el caso en su totalidad. Sin embargo, en la sentencia de esta instancia, la CIJ se declaró competente, pero reconoció "la soberanía sobre las islas de San Andrés, Providencia y Santa Catalina" (Corte Internacional de Justicia, 2007a: 47) por 13 votos contra 4 para Colombia, por lo cual, no se incorporó en la siguiente etapa.

Finalmente, en el año 2012 la CIJ por medio de su sentencia Territorial and Maritime Dispute (Nicaragua v. Colombia) (Corte Internacional de Justicia, 2012) territorializó el territorio importante para ambos Estados. En el capítulo "VI. Nicaragua solicita una declaración" (Corte Internacional de Justicia, 2007a: 97-100) se sentenció por votación: Primero, las islas Alburquerque, Bajo Nuevo, Cayos Este-Sudeste, Quitasueño, Roncasor, Serrana y Serranilla son de Colombia, por unanimidad. Segundo, es admisible la solicitud de Nicaragua de delimitación geográfica y legal en la costa continental, realizada en su presentación final, por 14 votos contra 1. Tercero, la reclamación por la costa continental realizada en la presentación final no es sostenible, por unanimidad. Cuarto, la CIJ hace un límite 
marítimo único para la plataforma continental y la zona económica exclusiva, por líneas geodésicas y coordenadas geográficas, por unanimidad. Quinto, alrededor de las islas y cayos, habrá un límite marítimo de arco de 12 millas marítimas (Ver Anexo 8), por unanimidad. Sexto, se rechaza la solicitud de declarar que Colombia no cumple con el derecho internacional, por no dejar que Nicaragua explote recursos naturales al este del Meridiano 82, por unanimidad.

De esta sentencia, se extraen las siguientes ideas. Primero, con respecto a las islas y cayos, unánimemente quedaron bajo la soberanía de Colombia incluyendo un arco de mar territorial de 12 millas. En consecuencia, existió un pensamiento único para la definición de ese espacio. Segundo, para la delimitación del mar, éste no abarcó la postura maximalista de ninguno de ambos Estados, repitiéndose la lógica del caso anterior. La CIJ distribuyó poder en la cuarta votación, definiendo los límites en un mapa a escala, por lo cual, como se aprecia en los anexos, la distribución del poder es por medio del cálculo y su representación cartográfica. Tercero, y al igual que la demanda anterior, hay cosas abiertas, continuando con Question of the delimitation of the continental shelf between Nicaragua and Colombia beyond 200 nautical miles from the Nicaraguan coast (República de Nicaragua, 2013a) para definir una zona de solapamiento más allá de las 200 millas marítimas, es decir, se solicita una delimitación y demarcación. Posteriormente, fue la demanda Alleged violations of sovereign rights and maritime spaces in the Caribbean Sea (República de Nicaragua, 2013b) relacionada con una cuestión fronteriza, dado que Colombia no respeta el límite internacional fijado por la CIJ el año 2012. Ambas demandas fueron presentadas durante el gobierno de Daniel Ortega.

\section{Costa Rica contra Nicaragua}

La demanda de Costa Rica contra Nicaragua, Maritime delimitation in the Caribbean Sea and the Pacific Ocean (República de Costa Rica, 2014) presentada por el gobierno de Laura Chinchilla, tiene como disputa el "establecimiento de un límite marítimo único entre los dos Estados en el Mar Caribe y en el Océano Pacífico" (República de Costa Rica, 2014: 04) siendo el espacio para territorializar $\mathrm{y}$ territorio importante el mar.

De manera general, la demanda puso dos territorios importantes, el Mar Caribe, donde había una diferencia sobre el límite marítimo y su origen (Ver Anexo 9 y Anexo 10); y el Océano Pacífico, donde había diferencia sobre el límite marítimo pero no el origen del mismo (Ver Anexo 12). De manera inversa a los casos anteriores, Nicaragua negaba la existencia de algo pendiente, mientras que Costa Rica señalaba la inexistencia de un límite. Como observación, hay una conducta propia del demandante y del demandado en los casos seleccionados.

La controversia, se hace justiciable por medio del Estatuto y Reglamento de la CIJ y el Pacto de Bogotá (República de Costa Rica, 2014: 04), solicitando que:

Determine el curso completo de un límite marítimo único entre todas las áreas marítimas pertenecientes, respectivamente, a Costa Rica y Nicaragua en el Mar Caribe y en el Océano Pacífico, sobre la base del derecho internacional [...] que determine las coordena- 
das geográficas precisas del límite marítimo único en el Mar Caribe y en el Océano Pacífico (República de Costa Rica, 2014: 08).

En la cita se observa que el territorio importante es el Mar Caribe y el Océano Pacífico, siendo ésta la competencia geopolítica. Se reitera, el que se haga acorde al derecho internacional, requiriendo el uso de coordenadas geográficas.

Costa Rica describe varios antecedentes sobre la disputa, como lo hizo Nicaragua al ser demandante. Primero, que en 2002 propuso negociar bilateralmente un límite internacional para el Mar Caribe y Océano Pacífico, que la contraparte detuvo el 2005; que tras el fallo de Nicaragua contra Colombia, Nicaragua definió un límite marítimo con Costa Rica por considerarlo implícito en la sentencia; que en marzo de 2013, Costa Rica invitó nuevamente a Nicaragua a negociar, sin haber interés por la contraparte, luego en julio se reiteró la invitación, pero Nicaragua no respondió (República de Costa Rica, 2014: 06). Segundo, y similar a lo que argumentaba Nicaragua contra Honduras y contra Colombia, aparecen como antecedentes la Convención del Mar de 1982, la jurisprudencia de la CIJ, la Constitución Política de 1949, que reclamaba un mar territorial de doce millas marítimas, zona económica exclusiva de 200 millas marítimas y plataforma continental (República de Costa Rica, 2014: 08).

Casi tres años después, Costa Rica presenta una nueva demanda contra Nicaragua, Land boundary in the northern part of Isla Portillos (República de Costa Rica, 2017), pero durante el gobierno de Luis Solís. En este caso, la disputa es por "la ubicación precisa del límite terrestre [...] establecimiento ilegal de un campamento militar por Nicaragua" (República de Costa Rica, 2017: 06), precisando como espacio para territorializar y territorio importante la tierra. Esta demanda complementa la anterior. De hecho, Costa Rica solicita la fusión de ambas. Por otra parte, esta demanda es consecuencia de otra, llamada Certain activities carried out by Nicaragua in the border area (República de Costa Rica, 2010) que fue sentenciada el año 2015 (Corte Internacional de Justicia, 2015).

La solicitud a la CIJ, es a base su Reglamento y Estatuto, junto con el Pacto de Bogotá (República de Costa Rica, 2017: 06 y 08):

(a) Para determinar la ubicación precisa del límite terrestre que separa ambos extremos del banco de arena Los Portillos / Harbor Head Lagoon de Isla Portillos [...] (b) Para adjudicar y declarar que, al establecer y mantener un nuevo campamento militar en la playa de Isla Portillos, Nicaragua ha violado la soberanía e integridad territorial de Costa Rica y ha violado la sentencia de la Corte del 16 de diciembre de 2015" (República de Costa Rica, 2017: 18).

A la sazón, la competencia geopolítica se define tanto por un asunto de límites, al fijarse la cuestión terrestre en Isla Portillos, como por un asunto de frontera, donde Nicaragua actúa como Estado invasor, siendo estos dos los territorios importantes. Se destaca que la delimitación solicitada no se basa en convenciones 
internacionales, siendo una variante a los casos anteriores, que se explica por ser tierra y no mar.

Los antecedentes son de corta data, parten por un incidente fronterizo, cuando Nicaragua se instaló militarmente en la parte norte de la Isla Portillos en noviembre de 2010, que llevó al gobierno de Costa Rica a interponer la demanda-Certain activities carried out by Nicaragua in the border area- antes señalada y que finalizó el año 2015 (República de Costa Rica, 2017: 08). Al año siguiente el asunto continuó y tras un último reclamo bilateral, el gobierno de Solís decidió demandar (República de Costa Rica, 2017: 18). Costa Rica también presentó el Tratado de Límites de 1858, el Laudo Cleveland y los Laudos Alexander de 1897, la sentencia de 2015 de la CIJ como antecedentes al caso (República de Costa Rica, 2017: 16).

A modo de síntesis, Costa Rica inició una disputa en una lógica y conducta similar a Nicaragua en los casos anteriores. Sobre el mar, la competencia geopolítica se extiende al Mar Caribe y el Océano Pacífico, pero sin incluir islas o cayos. Con la segunda demanda, se incorpora la tierra y la definición de la Isla Portillos en su límite internacional. Los antecedentes para territorializar el espacio, son la historia bilateral y el derecho internacional.

El resultado de ambas demandas se escribió en una sola sentencia, la Maritime delimitation in the Caribbean Sea and the Pacific Ocean and Land boundary in the northern part of Isla Portillos (Corte Internacional de Justicia, 2018). En el "Párrafo 205" (Corte Internacional de Justicia, 2018: 94-95) votó: Primero, la reclamación de Nicaragua sobre la costa norte de la Isla Portillos es admisible, 15 contra 1. Segundo, Costa Rica tiene soberanía sobre toda la parte norte de Isla Portillos (Anexo 14), 14 contra 2. Tercero (a) el campamento militar nicaragüense en territorio de Costa Rica, ha violado su soberanía, 14 contra 2. Tercero (b) Nicaragua debe sacar el campamento militar de Costa Rica, unánimemente. Cuarto, define el límite del Mar Caribe (Anexo 11), unánimemente. Quinto, define el límite en el Océano Pacífico (Ver Anexo 13), unánimemente.

A modo de comentario de esta sentencia. Primero, la CIJ cerró el tema, dado que no invita a las partes a solucionar otro tema o, por lo menos, tras la sentencia no ha habido información que indique lo contrario. Entonces, podría suponerse que existe una detención del proceso de territorialización. Segundo, la cuestión fronteriza es solucionada, cumpliéndose la solicitud demandada por Costa Rica de retiro del campamento militar de Isla Portillo. Tercero, se establece un límite terrestre y dos límites marítimos. En ambos casos existe una cartografía a base de cálculos del espacio, por lo cual se hace un análisis del espacio para luego territorializarlo y convertirlo en territorio soberano entre los Estados. Una diferencia es que para lo territorial no existe unanimidad en la votación, mientras que para los límites marítimos sí lo hay, los cuales tampoco cumplen la visión maximalista de las partes.

\section{Conclusiones}

Elden señala que el territorio es un proceso continuo, lo cual es muy explicativo de los casos seleccionados, ya que estos son un episodio más de las disputas geopolíticas de América Central. La larga data de estas disputas demuestra que el 
espacio y su transformación en territorio, tiene un valor en sí mismo, sin importar el cambio de régimen internacional, régimen político y/o de gobierno, la competencia geopolítica persiste. El territorio tiene una lógica propia, que determina el comportamiento al no existir una conclusión, como ocurre con los cambios de gobierno en Nicaragua y Costa Rica.

Respondiendo la primera pregunta, sobre las características de las competencias geopolíticas, se concluye que: a) En todos los casos, el territorio valioso incluye mar y tierra, siendo el principal recurso el mar, ya que las delimitaciones marítimas incluyen posteriormente delimitaciones terrestres, y a su vez, su extensión y riqueza es mayor en comparación a la tierra. El principal espacio de mar disputado es el Mar Caribe, el cual está presente en tres de los casos seleccionados, sumándose el Océano Pacífico en Costa Rica contra Nicaragua. En este sentido, los recursos naturales, principalmente pesca y petróleo, son uno de los beneficios a recibir al quedarse con el territorio. La tierra, por otra parte, es por los cayos en Nicaragua contra Honduras; por las islas y cayos en Nicaragua contra Colombia; y por la Isla Portillos en Costa Rica contra Nicaragua; b) El comportamiento del Estado demandante es común en todos los casos: expone antecedentes históricos, cita al derecho internacional, intentó una solución bilateral y finalmente decide por la demanda. Por contraparte, los Estados demandados, tienen como conducta repetitiva: negar la existencia de un problema y que tal asunto estaría ya zanjado. Nicaragua es el Estado que mejor demuestra este comportamiento, ya que cumple el rol completo como demandante y demandado; c) La demanda es la estrategia para lograr objetivos geopolíticos en América latina, por lo que la demanda de Nicaragua contra Honduras es un hito para la consolidación de la estrategia justiciable en la región.

Sobre la segunda pregunta, relacionada con las características de las sentencias de la CIJ, se concluye: a) Las sentencias no son necesariamente la última fase del proceso de territorialización. Ello queda claro en Nicaragua contra Honduras, donde ambos Estados deben definir un pequeño espacio entre el límite terrestre y el marítimo; en el segundo, donde Nicaragua abre dos demandas más como corolario de la sentencia de la CIJ en contra de Colombia; y la cuarta demanda, es consecuencia del incumplimiento de una controversia anterior; b) Las técnicas para convertir el espacio en disputa en un territorio soberano se basan en la creación de cartografía apoyada con datos numéricos de coordenadas, es decir son escalas de los espacios en disputas ya territorializados, pero con una demarcación en papel, es decir, algo representativo; c) Para definir un espacio como territorio, se debe hacer una votación, por lo cual, la territorialización se hace colegiadamente. Dado que las votaciones no siempre son unánimes y que existen votos minoritarios, la interpretación del territorio es variable, existiendo más de una interpretación ante un mismo espacio con presencia de los mismos antecedentes.

Por último, la territorialización del territorio en el caso de las competencias geopolíticas analizadas, tiene una relación directa con el conocimiento más allá del cálculo. En detalle, la territorialización es interdisciplinaria, los Estados en controversia deben tener conocimiento de derecho internacional, en especial de 
convenciones y la jurisprudencia de la CIJ; de historia, en relación a cómo se han territorializado bilateralmente los espacios en disputas, de geografía, para tener claridad del territorio importante sometido a controversia y de cartografía, para aplicar sin dudas la sentencia de la CIJ.

\section{Anexos}

\section{Anexo 1}

Bosquejo de mapa $\mathbf{N}^{\circ} 2$. Líneas del límite marítimo demandado por Nicaragua y Honduras respectivamente

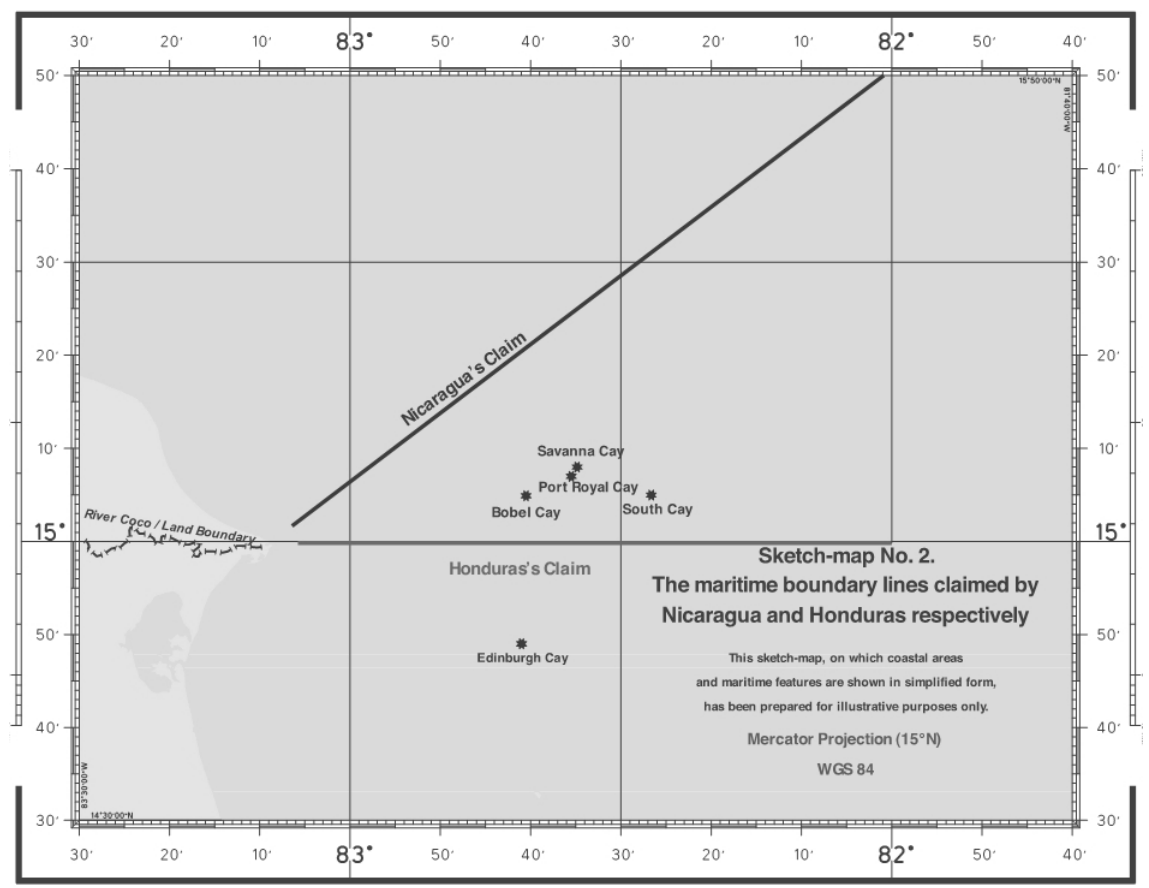

Fuente: CIJ, 2007: 686. 
Anexo 2

Bosquejo de mapa $\mathrm{N}^{\circ}$ 5. Límite en la vecindad de los cayos

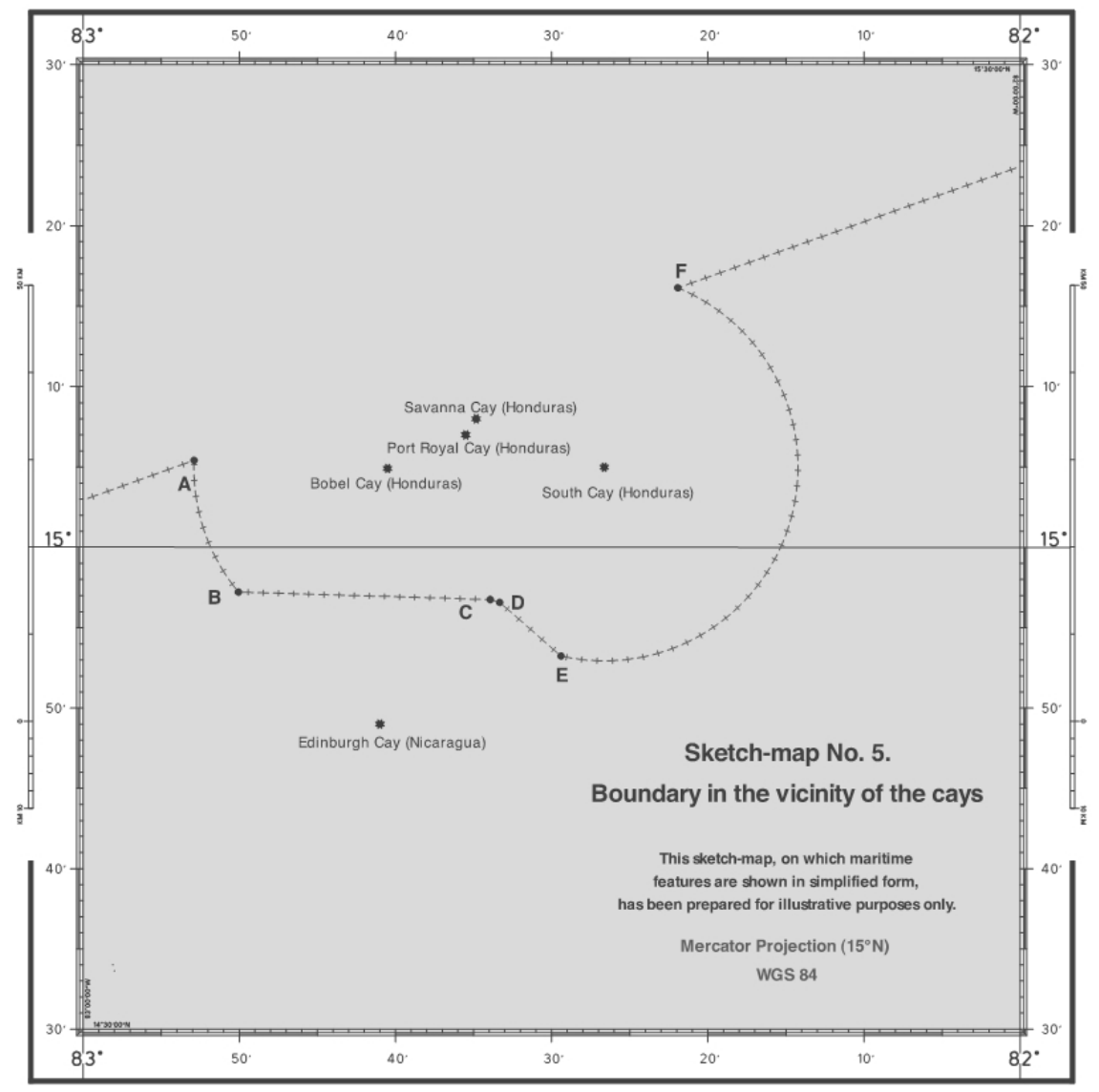

Fuente: CIJ, 2007:754. 
Anexo 3

Bosquejo de mapa $\mathrm{N}^{0}$ 6. Punto de partida del límite marítimo

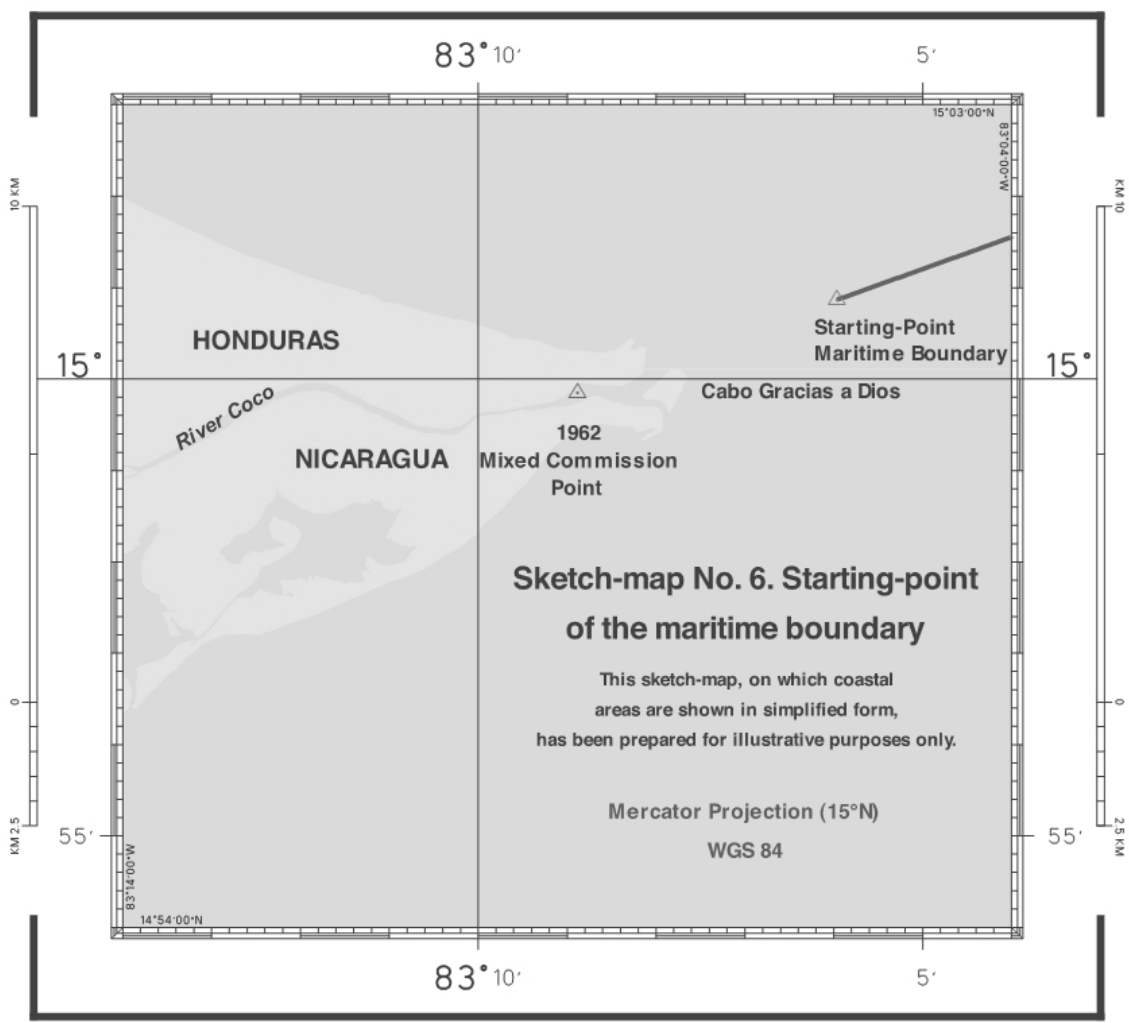

Fuente: CIJ, 2007:758. 
Anexo 4

Bosquejo de mapa $\mathbf{N}^{0}$ 7. Curso de la línea del límite marítimo

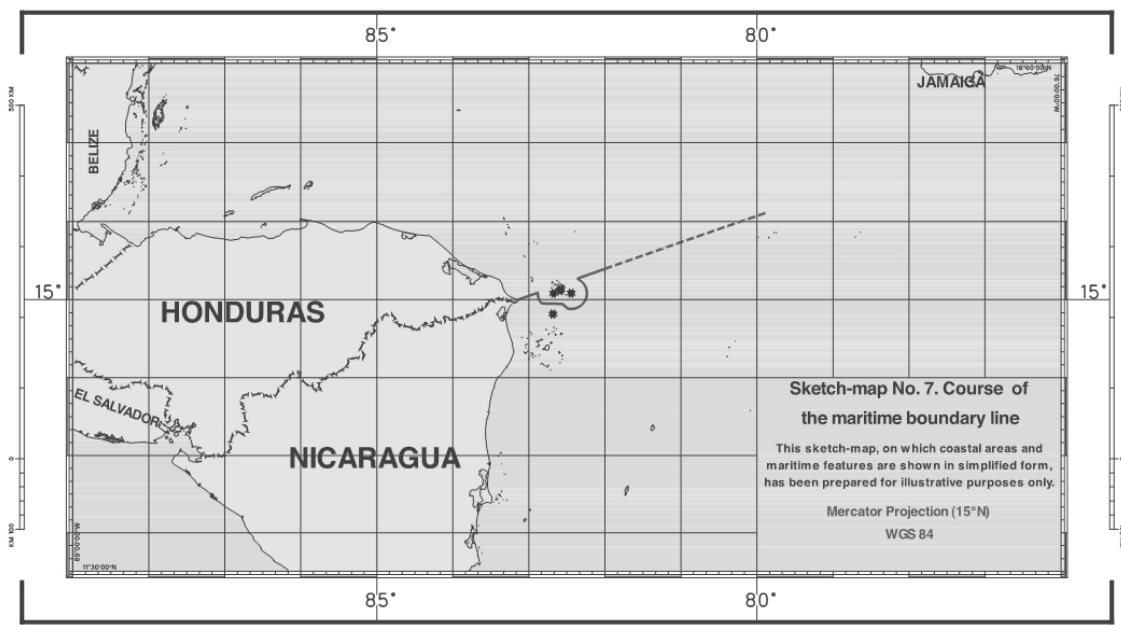

Fuente: CIJ, 2007:771.

Anexo 5

Bosquejo de mapa $\mathrm{N}^{0} 1$. Contexto Geográfico

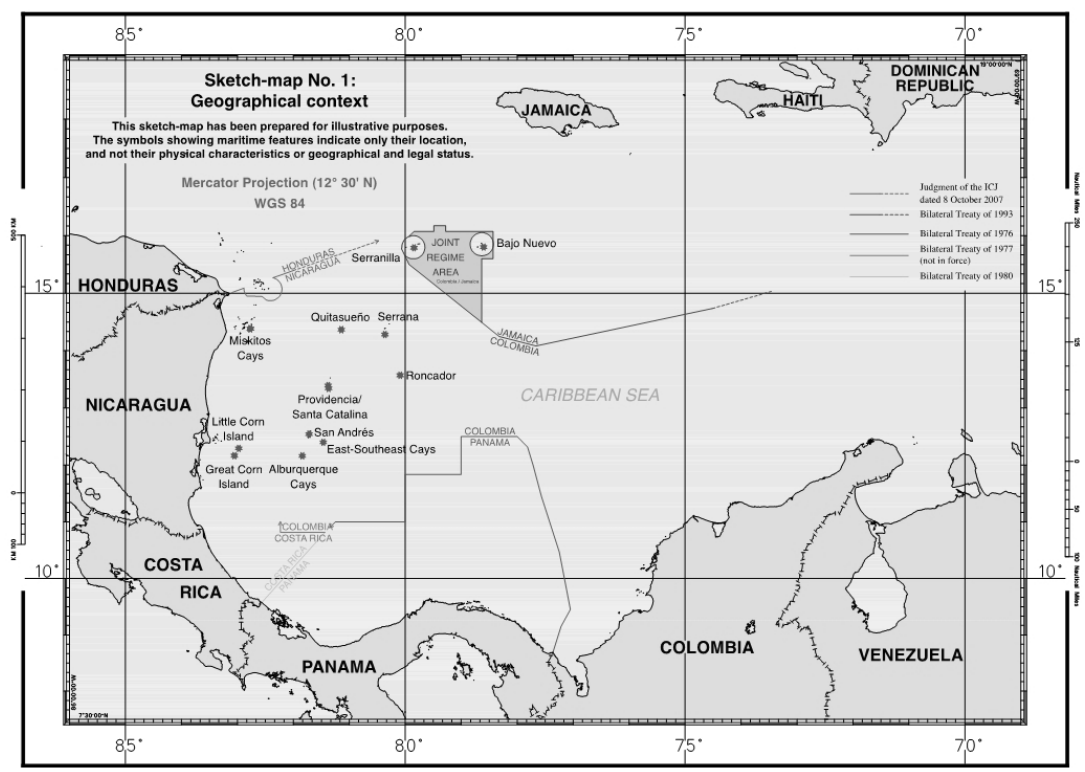

Fuente: CIJ, 2012: 639. 
Anexo 6

Bosquejo de mapa $\mathbf{N}^{0}$ 2. Delimitación demandada por Nicaragua

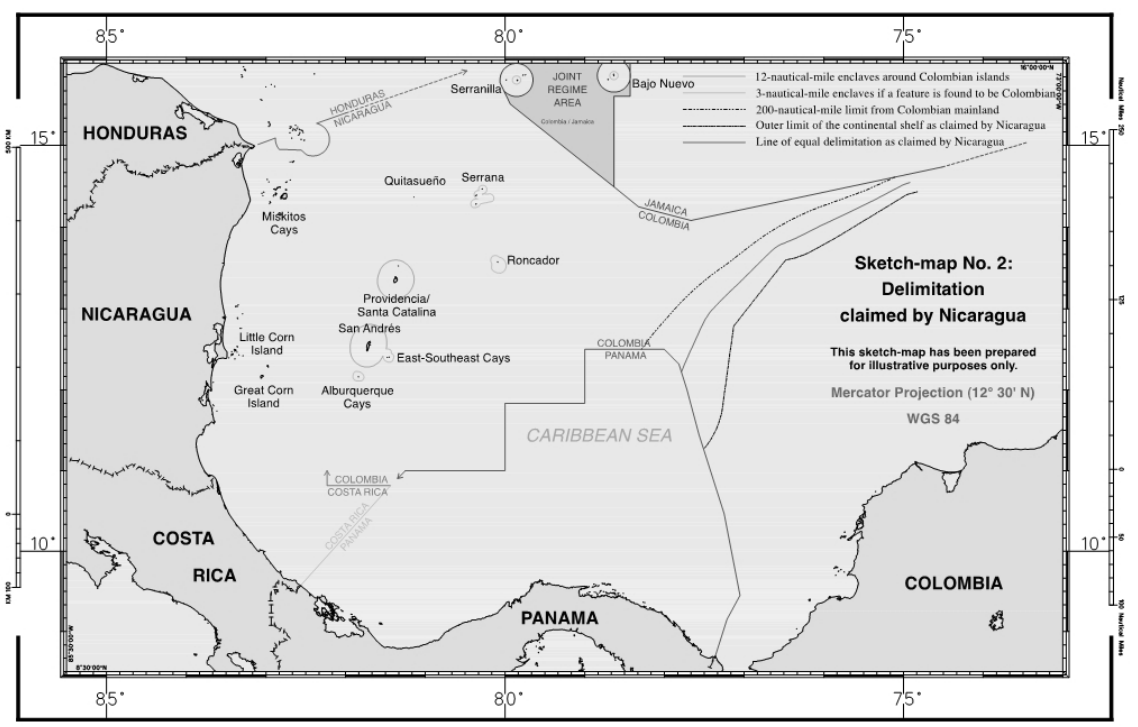

Fuente: CIJ, 2012: 672. 


\section{Anexo 7}

\section{Bosquejo de mapa $\mathbf{N}^{\circ} 3$. Delimitación demandada por Colombia}

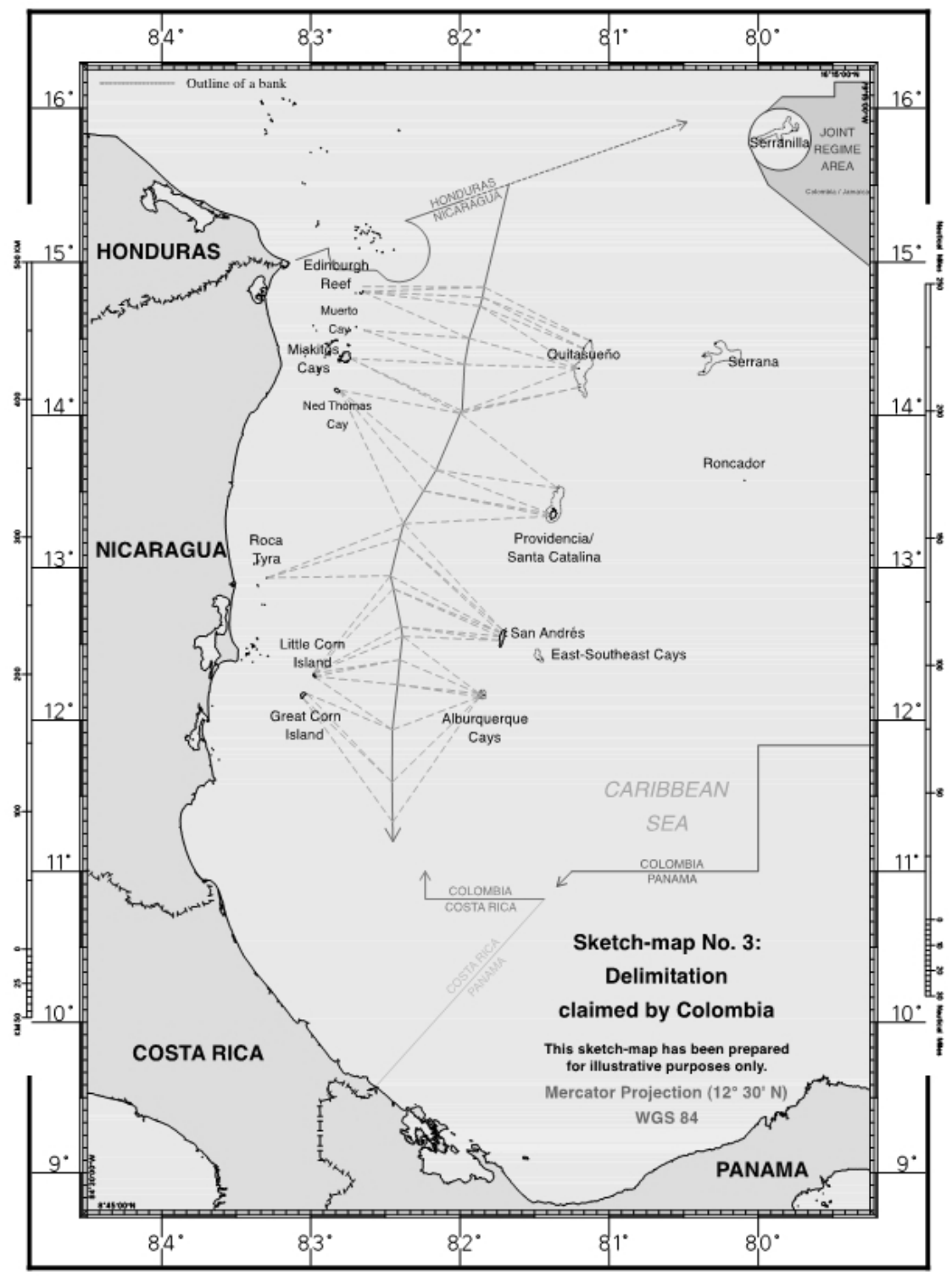

Fuente: CIJ, 2012: 663. 


\section{Anexo 8}

Bosquejo de mapa $\mathrm{N}^{\circ} 11$. Curso de la línea del límite marítimo

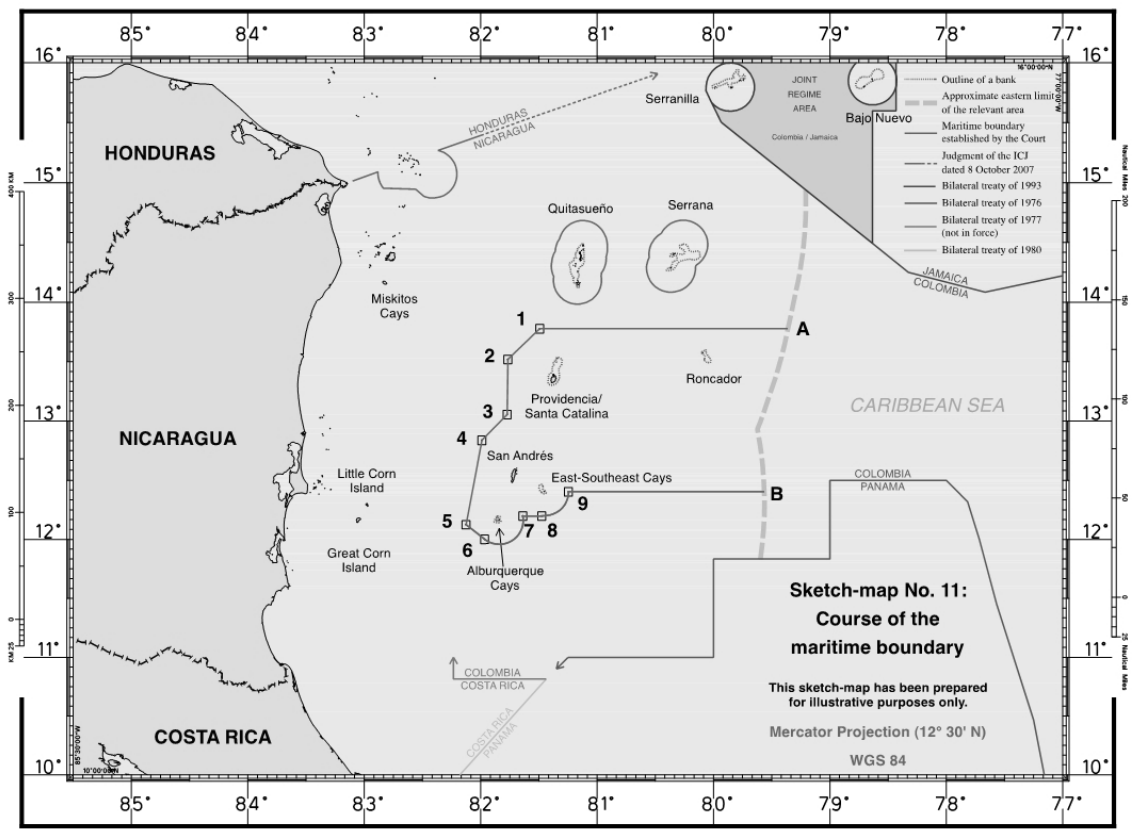

Fuente: CIJ, 2012: 714. 


\section{Anexo 9}

\section{Bosquejo de mapa $\mathbf{N}^{0} 3$}

Los límites marítimos reclamados por las partes en el Mar Caribe

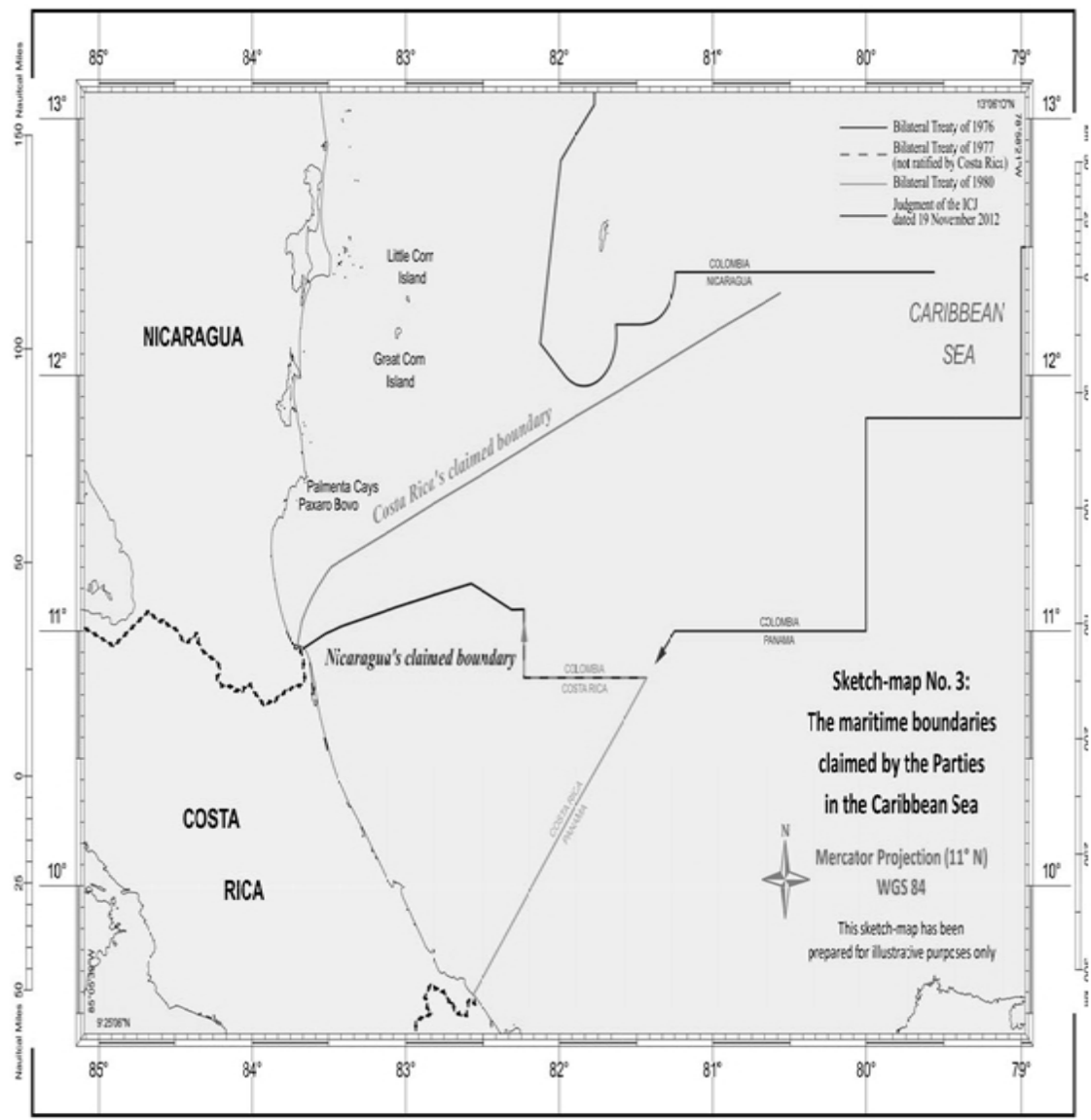

Fuente: CIJ, 2018: 35. 
Anexo 10

Bosquejo de mapa $\mathrm{N}^{\circ} 4$

Punto de partida del límite marítimo reclamado por las partes en el Mar Caribe

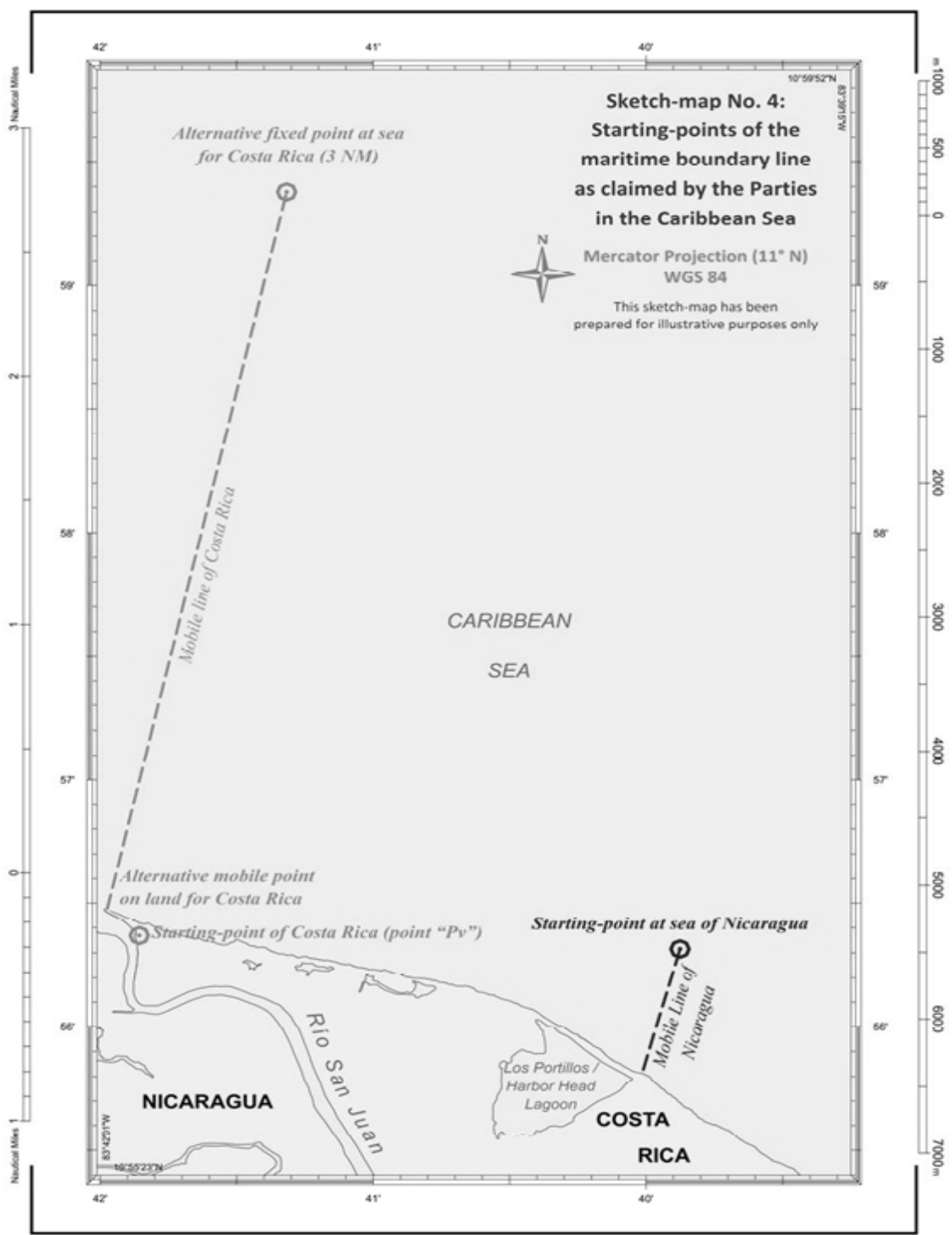

Fuente: CIJ, 2018: 37. 
Anexo 11

Bosquejo de mapa $\mathrm{N}^{0} 13$. Curso del límite marítimo

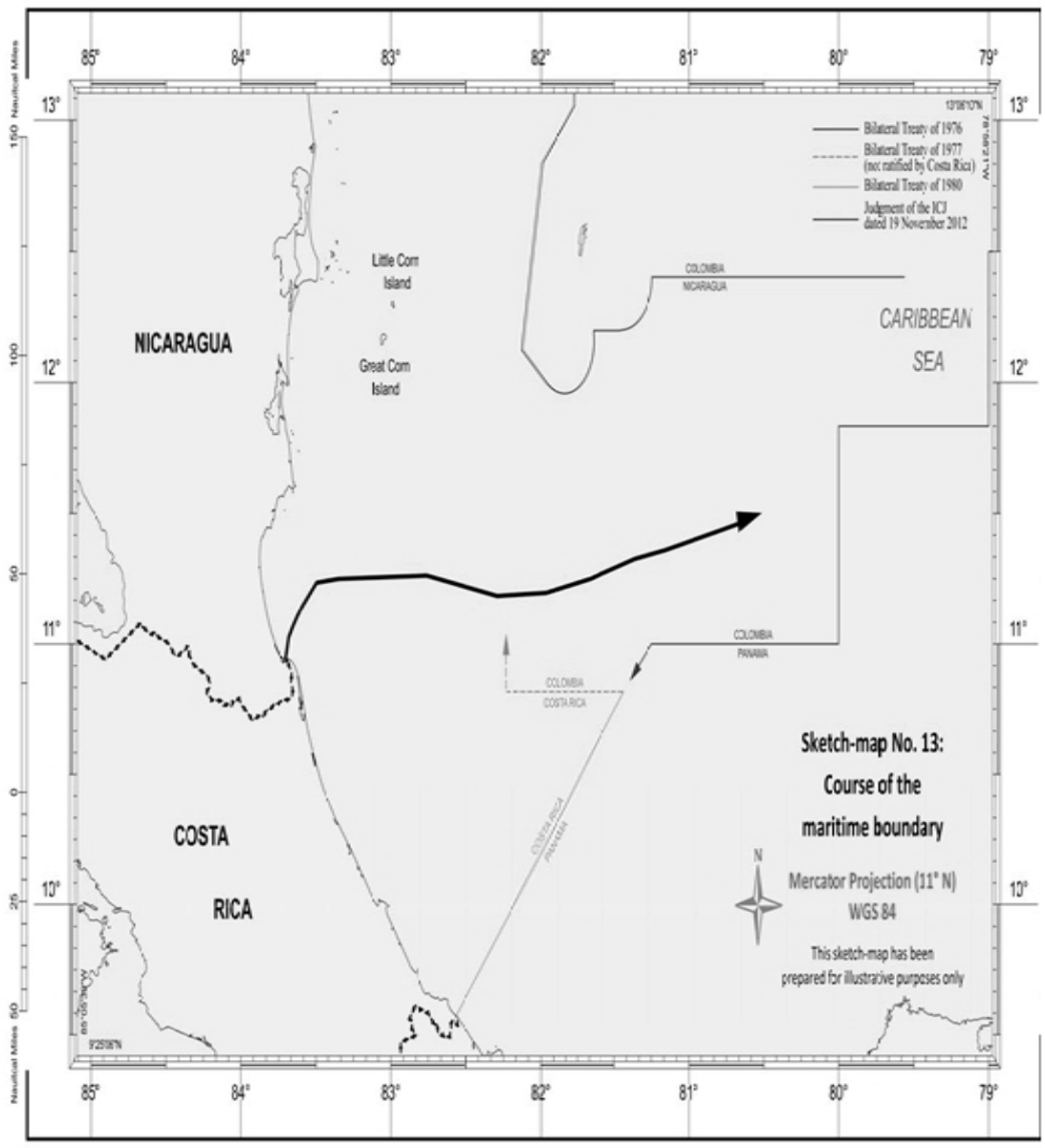

Fuente: CIJ, 2018: 68. 
Anexo 12

Bosquejo de mapa $\mathrm{N}^{0} 14$

Los límites marítimos reclamados por las partes en el Océano Pacífico

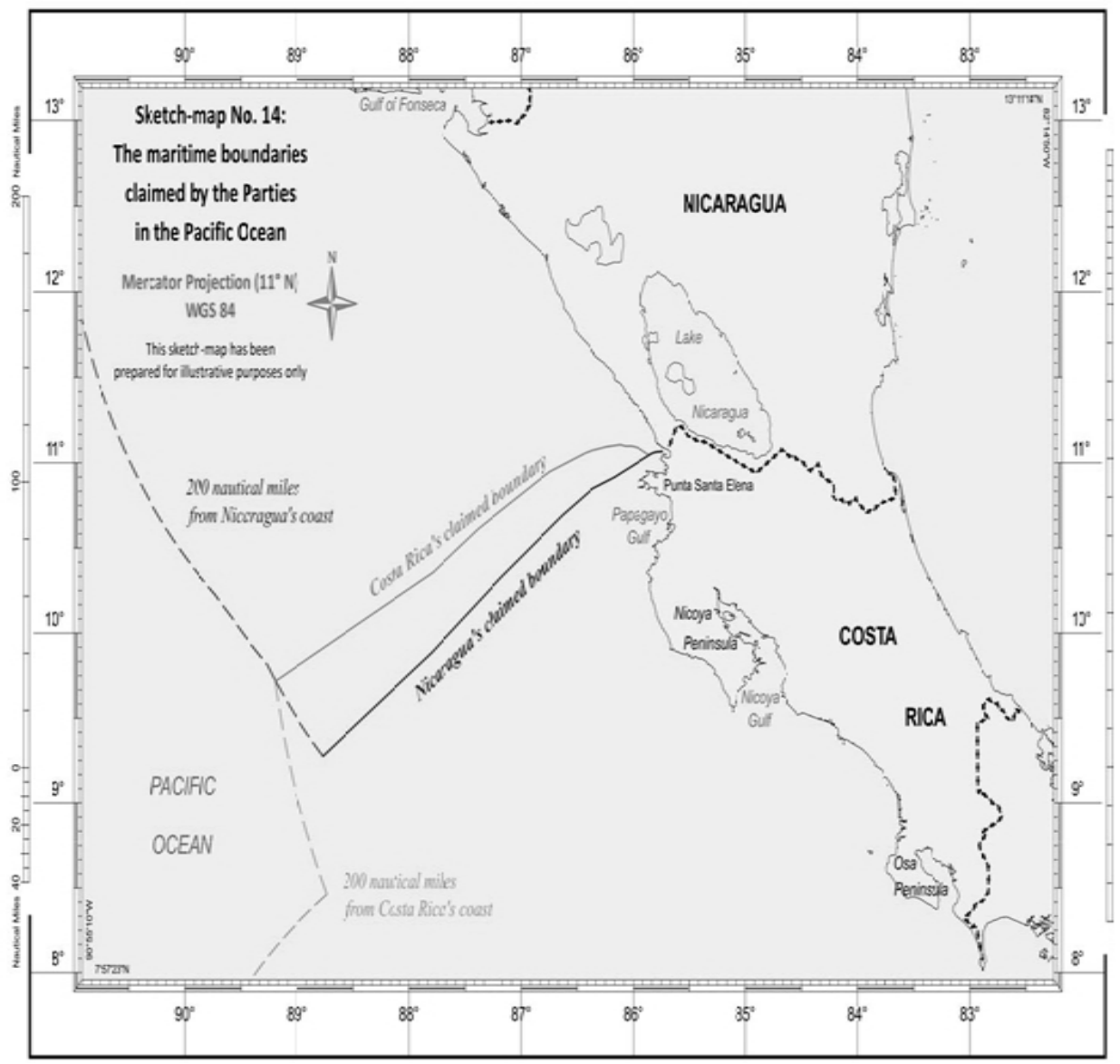

Fuente: CIJ, 2018: 70. 
Anexo 13

Bosquejo de mapa $\mathbf{N}^{\circ} 22$. Curso del límite marítimo

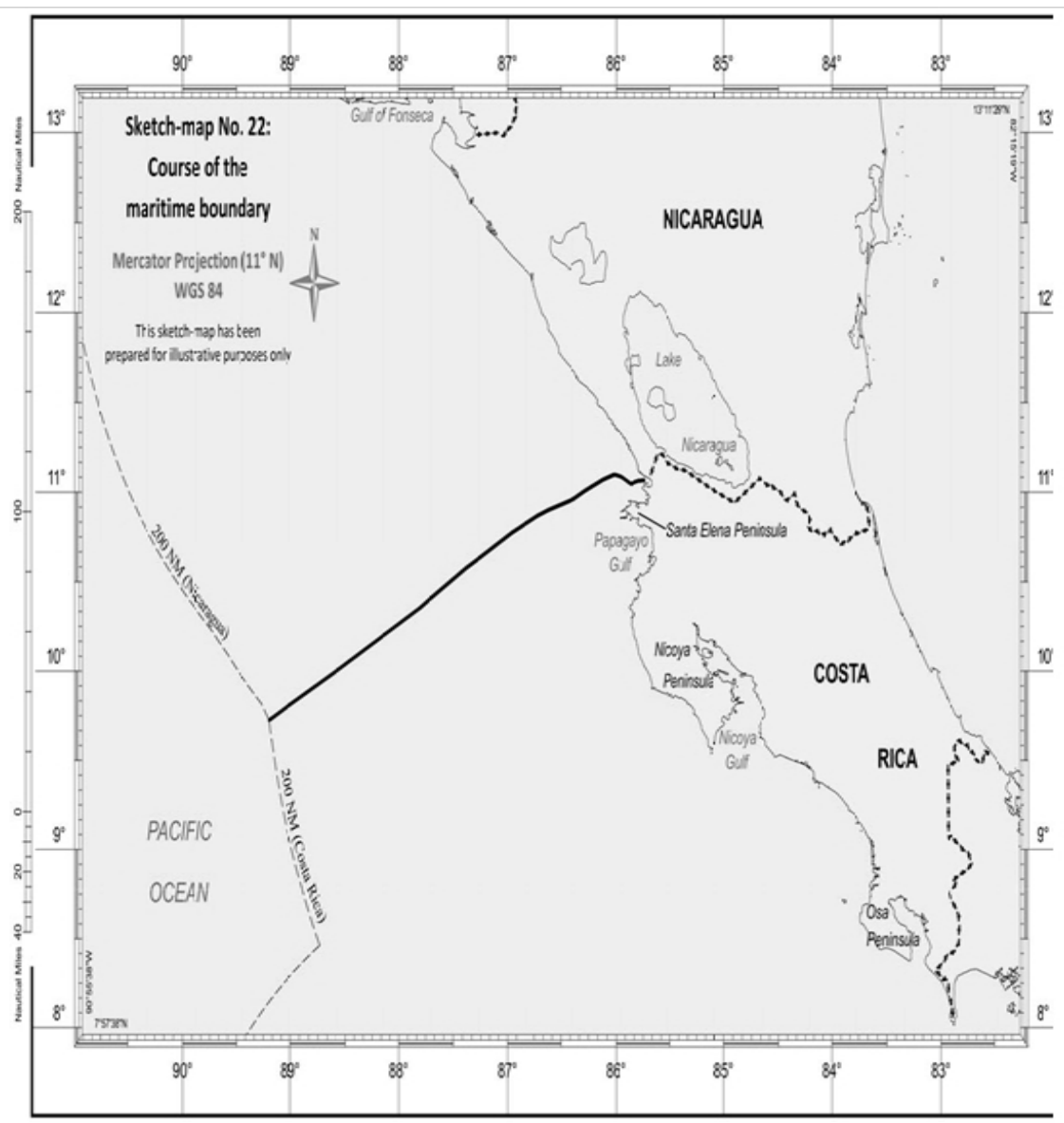

Fuente: CIJ, 2018: 93. 
Anexo 14

Bosquejo de mapa $\mathrm{N}^{\circ}$ 2. Límite terrestre en la parte norte de la Isla Portillos

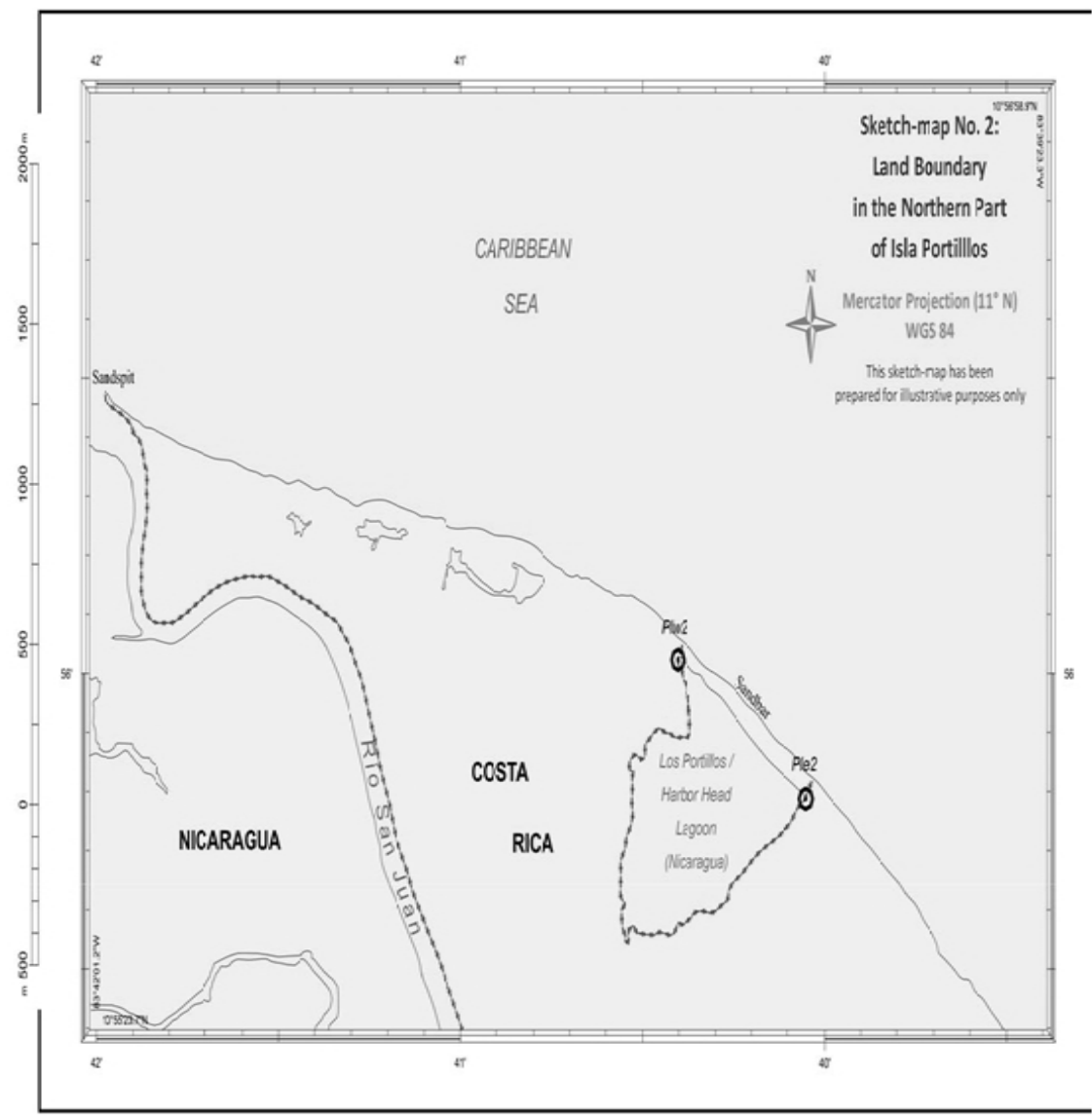

Fuente: CIJ, 2018: 33. 


\section{Referencias}

* El autor agradece al Profesor PhD Luis Lobo-Guerrero, quien en el Seminario de Investigación "Geopolitics and connectivities" del Master of Arts International Relations \& International Organizations, 2017-2018, University of Groningen, estimuló el estudio del tema presentado y al Programa Becas Chile de CONICYT, perteneciente al Ministerio de Educación del Estado de Chile, que por medio de la beca número 73160592, financió el programa de Master antes mencionado.

\section{Bibliografía}

Abello, R. (2013). Chapter 4: Contentious function. Introduction to International Court of Justice: ICJ, Colombia, Universidad del Rosario, 38-60.

Alvarado, O. (2014). El conflicto fronterizo entre Colombia y Nicaragua: recuento histórico de una lucha por el territorio. Historia Caribe, IX. 25: 241-271.

Barrios, M. (2009). Geopolítica. Diccionario latinoamericano de seguridad y geopolítica, Buenos Aires, Editorial Biblos, 193-198.

Behr, H. (2007). Political Territoriality and De-Territorialisation. Area Review, (39). 1: 112-115.

Bellei, C. (2015). ¿Existen aún disputas internacionales no-justiciables en virtud de su carácter político? La práctica de la Corte Internacional de Justicia. Anuario Mexicano de Derecho Internacional, XV: 93-135.

Blomley, N. (2016). The territory of property. Progress in Human Geography, (40). 5: 593-609.

Buxbaum, H. (2009). Territory, Territoriality, and the Resolution of Jurisdictional Conflict, The American Journal of Comparative Law, 57. 3: 631-675.

Corte Internacional de Justicia (2007a). Territorial and Maritime Dispute between Nicaragua and Honduras in the Caribbean Sea (Nicaragua v. Honduras), Judgment, I.C.J. Reports, 8 October.

Corte Internacional de Justicia (2007b). Territorial and Maritime Dispute (Nicaragua v. Colombia), Preliminary Objections, Judgment, I.C.J. Reports, 13 December.

Corte Internacional de Justicia (2012). Territorial and Maritime Dispute (Nicaragua v. Colombia), Judgment, I.C.J. Reports, 19 November.

Corte Internacional de Justicia (2015). Certain Activities Carried Out by Nicaragua in the Border Area (Costa Rica v. Nicaragua) and Construction of a Road in Costa Rica along the San Juan River (Nicaragua v. Costa Rica), Judgment, I.C.J. Reports, 16 December.

Corte Internacional de Justicia (2018). Maritime delimitation in the Caribbean Sea and the Pacific Ocean (Costa Rica v. Nicaragua) and Land boundary in the northern part of Isla Portillos (Costa Rica v. Nicaragua), Judgment, I.C.J. Reports 2018, 2 February.

Dellanegra, L. (2010). Teoría y metodología de la geopolítica. Hacia una geopolítica de la "construcción de poder", Revista Mexicana de Ciencias Politicas y Sociales, LII: 15-42.

Elden, S. (2005). Missing the Point: Globalization, Deterritorialization and the Space of the World, Transactions of the Institute of British Geographers, New Series, volumen 30. 1: 8-19.

Elden, S. (2007). Governmentality, calculation, territory, Environment and Planning D: Society and Space, volumen 25: 562-580.

Elden, S. (2010). Land, terrain, territory, Progress in Human Geography, 34. 6: 799-817.

Elden, S. (2013a). Introduction y Coda, The Birth of Territory, Chicago: University of Chicago Press: $1-18 ; 322-330$.

Elden, S. (2013b). How Should We Do the History of Territory?, Territory, Politics, Governance, 1: $5-20$.

Kojima, C. (2017). Territorial and Maritime dispute between Nicaragua and Honduras in the Caribbean Sea (Nicaragua v. Honduras), 1999. Latin America and the International Court of Justice Contributions to International Law, Ed. Wojcikiewicz, Paula; Sorel, Jean-Marc. United Kingdom: Routledge, 250-261.

Manzano, K. y Jiménez, D. (2016). El papel geopolítico de la Corte Internacional de Justicia en América del sur: el caso Perú-Chile (2008-2014), Revista de Relaciones Internaciones, Estrategia y Seguridad, volumen 11. 2: 187-214.

Medina, L. (2013). Una interfaz transfronteriza compleja. El caso del Golfo de Fonseca: El Salvador, 
Honduras y Nicaragua, Revista LiminaR, Estudios Sociales y Humanísticos, volumen XI. 2: 54-69.

Quesada, M. (2014). Disputa fronteriza y valor geoestratégico del río San Juan: Nicaragua y Costa Rica, Cuadernos de Geografia: Revista colombiana de Geografia, volumen 23. 2: 69-83.

Raffestin, C. (2012). Space, territory, and territoriality, Environment and Planning D: Society and Space, volumen 30: 121-141.

República de Costa Rica. Application, instituting proceedings (2010). Certain activities carried out by Nicaragua in the border area (Costa Rica v. Nicaragua), 18 November.

República de Costa Rica. Application, instituting proceedings (2014). Maritime delimitation in the Caribbean Sea and the Pacific Ocean (Costa Rica v. Nicaragua), 25 February.

República de Costa Rica. Application, instituting proceedings (2017). Land boundary in the northern part of Isla Portillos (Costa Rica v. Nicaragua), 16 January.

República de Nicaragua. Application, instituting proceedings (1999). Maritime delimitation between Nicaragua and Honduras in the Caribbean Sea (Nicaragua v. Honduras), 8 December.

República de Nicaragua. Application, instituting proceedings (2001). Territorial and Maritime dispute (Nicaragua v. Colombia), 6 December.

República de Nicaragua. Application, instituting proceedings (2013a). Question of the delimitation of the continental shelf between Nicaragua and Colombia beyond 200 nautical miles from the Nicaraguan coast (Nicaragua v. Colombia), 16 September.

República de Nicaragua. Application, instituting proceedings (2013b). Alleged violations of sovereign rights and maritime spaces in the Caribbean Sea (Nicaragua v. Colombia), 26 November.

Reichert, R. (2017). El golfo de Honduras: estrategias geopolíticas y militares de una frontera imperial, siglos XVI-XVIII, Tzintzun. Revista de Estudios Históricos, 65: 09-40.

Roszko, E. (2015). Maritime territorialisation as performance of sovereignty and nationhood in the South China Sea, Nations and Nationalism, 21. 2: 230-249.

Sánchez-Aguirre, R. (2015). Límites y equilibrios de poder en la disputa por un territorio insular caribeño: el caso de San Andrés (1970-1991), Entramado 11, 1: 106-123.

Scovazzi, T. (2017). Maritime Dispute (Peru v. Chile), 2008, Latin America and the International Court of Justice Contributions to International Law, Ed. Wojcikiewicz, Paula; Sorel, Jean-Marc. United Kingdom: Routledge, 237-249.

Tassin, V. (2017). Territorial and Maritime (Nicaragua cv. Colombia), 2001, Latin America and the International Court of Justice Contributions to International Law, Ed. Wojcikiewicz, Paula; Sorel, Jean-Marc. United Kingdom: Routledge, 225-236.

Wojcikiewicz, Paula; Sorel, Jean-Marc. (2017). Latin America and the International Court of Justice Contributions to International Law, United Kingdom, Routledge.

Xuan To, P. (2015). State Territorialization and Illegal Logging: The Dynamic Relationships between Practices and Images of the State in Vietnam, Critical Asian Studies, 47. 2: 229-252

Recibido: 12/04/2019. Aceptado: 25/05/2019.

Pablo Rivas Pardo, "Las competencias geopolíticas de Nicaragua, Honduras, Colombia y Costa Rica por su territorio ante la Corte Internacional de Justicia". Revista Temas y Debates. ISSN 1666-0714, año 23 , número 38, julio-diciembre 2019, pp. 121-147. 